\title{
Peertechz
}

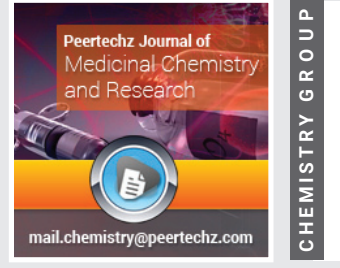

Opinion

\section{Biofuels and biochemicals}

\section{from biomass}

\author{
Indra Neel Pulidindi and Aharon Gedanken*
}

Department of Chemistry, Bar Ilan University, Ramat Gan, Israe
Received: 29 January, 2021

Accepted: 10 February, 2021

Published: 11 February, 2021

*Corresponding author: Aharon Gedanken, Department of Chemistry, Bar Ilan University, Ramat Gan, Israel, Email: gedanken@mail.biu.ac.il, indraneelp@ rediffmail.com

ORCID: https://orcid.org/0000-0002-3281-9649

https://www.peertechz.com

Check for updates
Among various renewable energy sources, namely, biomass, solar, wind, hydrothermal and geothermal, biomass standout as an environmentally benign, sustainable and an immediate substitute to fossil based fuels. This is due to the abundance of the carbon source in the form of cellulose in the biomass. Cellulose is the major chemical constituent of terrestrial biomass (40-50 wt.\%, percentage by weight) with the other constituents being hemicellulose and lignin. However, owing to the extensive inter and intramolecular hydrogen bonding network existing in the cellulose structure, depolymerization of cellulose to monomeric carbohydrate glucose is nearly two orders of magnitude difficult than the hydrolysis of starch to glucose. The extensive inter and intramolecular hydrogen bonding network that hinders the access of acidic proton of the catalyst to attack the reaction site of $\beta-1,4$ glycosidic bonds of cellulose (the linear homopolymer of glucose) is shown pictorially in Figure 1. The hydrogen bonding network within a single chain of glycose polymer in the cellulose structure is called intramolecular hydrogen bonding while such bonding between two neighbouring linear chains of glucose polymers is called as intermolecular hydrogen bonding. The bond energy of such hydrogen bonding is $2 \mathrm{eV}$ which is nearly 3-6 orders of magnitude higher than microwave energy $\left(1.24 \times 10^{-6}-1.24\right.$ $10^{-3} \mathrm{eV}$ ) [1]. Yet, with the application of unconventional and novel methods of activation like microwave irradiation, the acid catalyzed hydrolysis of biomass (cellulose) to monosaccharides is accelerated by facilitating the access of the acidic proton of the chemical catalyst to the reaction site, namely, $\beta-1,4$ glycosidic bonds. Such unusual activation of the cellulose structure making it conducive for the catalytic conversion selectively to glucose by microwave irradiation is possible owing to the peculiar phenomena called "threshold effect".

This means, that beyond a particular value of microwave power, because of the non-thermal effects of microwave waves, the structure and dynamics of the tetrahedral structure of water with hydrogen bonding network is drastically

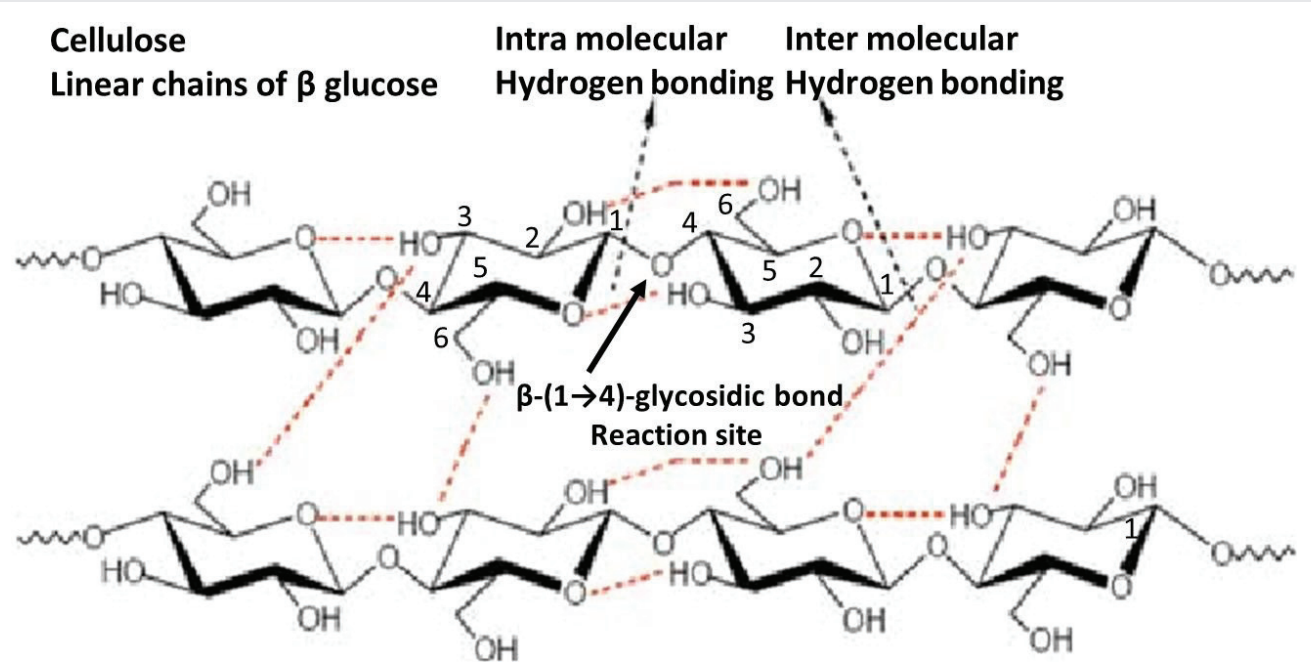

Figure 1: Extensive inter and intramolecular network prevailing in the cellulose structure. 
altered and moreover the hydrogen bonding lifetime and number of hydrogen bonds are drastically reduced [2]. In fact, experimental evidence for such hydrogen bonding activating power of microwave irradiation in the cellulose structure (commercial Avicel PH 101, cellulose from cotton linters), is observed upon microwave irradiation of cellulose in water medium in the presence of $\mathrm{HCl}$ catalyst (7.5 wt.\%, $2.38 \mathrm{M})$. The effect of microwave irradiation on the selective yield of glucose can be seen in Figure 2 [3]. Highest yield of $0.67 \mathrm{~g}$ glucose $/ \mathrm{g}$ cellulose is obtained upon microwave irradiation for 7 minutes. The microwave irradiation of $1 \mathrm{~g}$ cellulose in $20 \mathrm{~mL}$ distilled water was carried out in a regular domestic microwave oven modified to have the provision for stirring and refluxing.

Such high and selective yield of glucose in short duration is achieved using microwave irradiation without any pretreatment of cellulose or the use of special solvents, like ionic liquids, that enhance the performance of microwave heating. Cellulose hydrolysis is not the only reaction wherein the potential of microwave irradiation for selective glucose production is demonstrated. Microwave irradiation was proved to be promising for the acceleration of transesterification of lipids to biodiesel and for the pretreatment of biomass. Analogous to microwave irradiation, ultrasound irradiation was also proved to be a promising method for accelerating the biomass conversion processes like lipid extraction from microalgae, transesterification of triglycerides and fermentation of carbohydrates to bioethanol. However, unfortunately, these unconventional methods of activation are underutilized in biofuel production as see in Figure 3.

Even though the laboratory scale chemical reactions of biomass conversion are successful, the processes using these activation methods could not be scaled up to a pilot

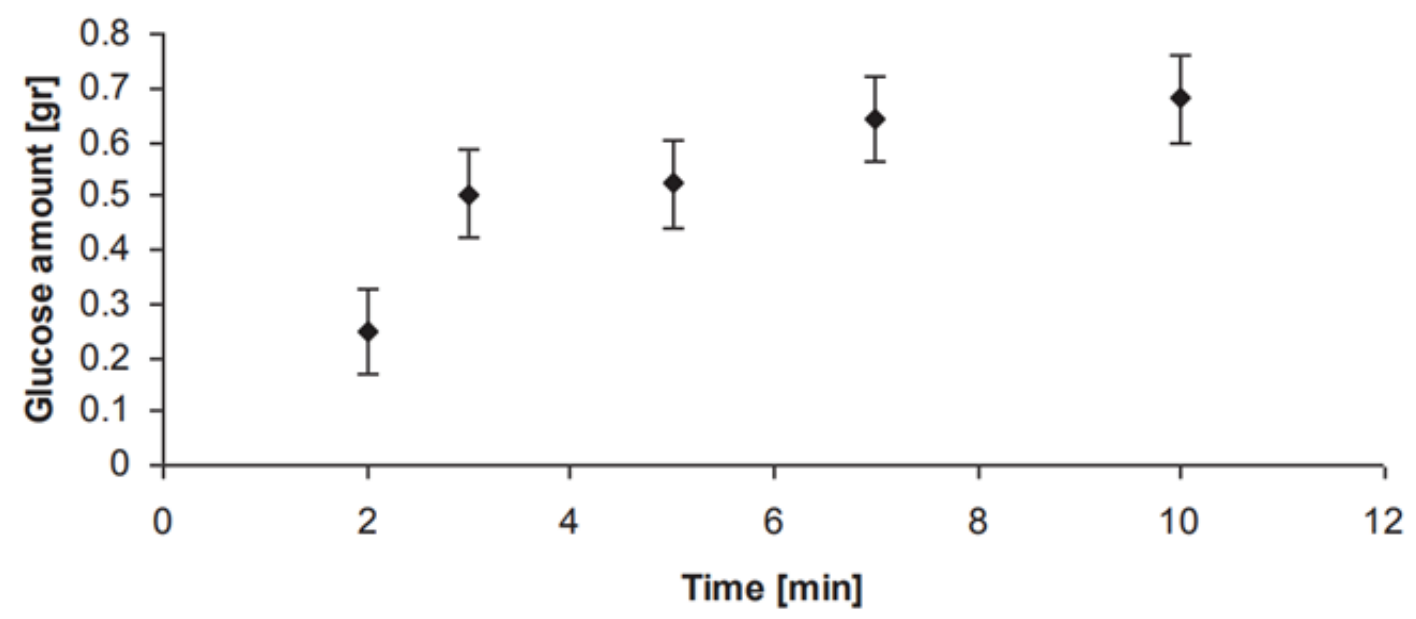

Figure 2: Effect of microwave irradiation time on the yield of glucose (Reaction conditions: $7.5 \mathrm{wt} . \% \mathrm{HCl} ; 1 \mathrm{~g}$ cellulose in $20 \mathrm{~mL}$ water; domestic microwave oven power: 1200 W; microwave frequency: $2.45 \mathrm{GHz}$ ). Adapted with permission from Elsevier [3].

\section{Research activity in \\ "Nontraditional methods of activation"}
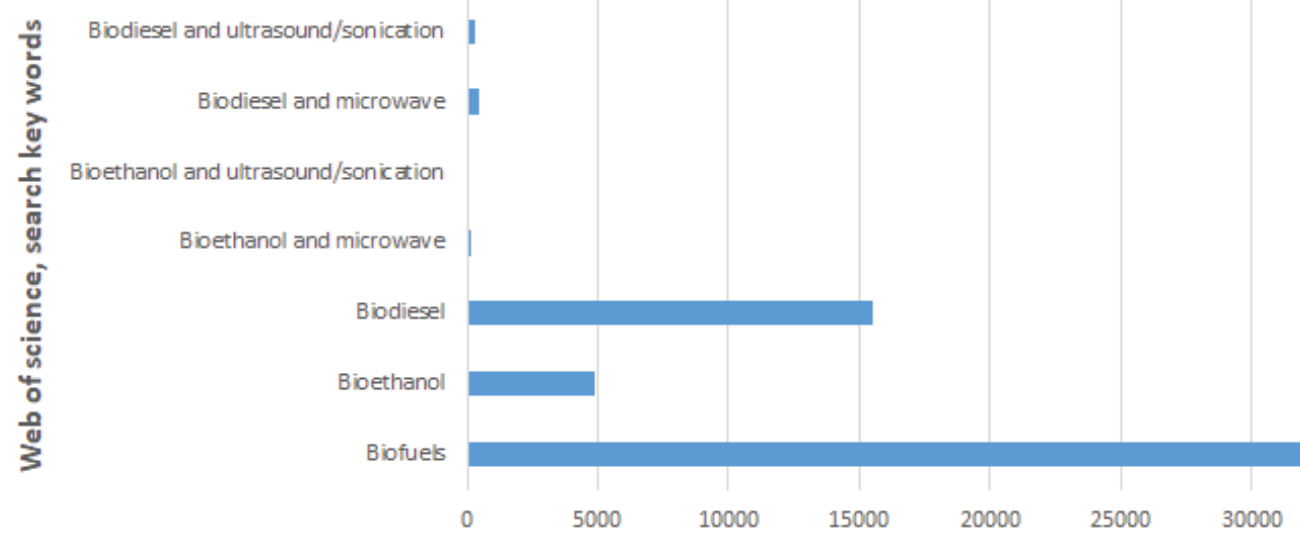

Web of science, search results, Years, 2018-2020

Figure 3: Research publications in the field of biofuels, biodiesel, bioethanol and the use of unconventional methods of activation, like microwave and ultrasound/ sonochemical irradiation, in biofuels production.

Citation: Pulidindi IN, Gedanken A (2021) Biofuels and biochemicals from biomass. Open Journal of Chemistry 7(1): 022-024 
plant level or industrial level operations. In addition to the ingenuity of chemists, innovation from engineers in designing large microwave and sonochemical devices is expected. The number of publications on the topics of biofuels, biodiesel and bioethanol in the years $2018-2020$ are $31,909,15,503$, and 4,854 respectively indicating that the interest in this field is enormous. However the use of novel methods of activation like microwave and ultrasound/sonochemical irradiation is orders of magnitude lower in biodiesel and bioethanol production. Maturity in microwave technology especially, with respect to the scaling of the equipment suiting the chemical processes, like trans esterification of lipids and hydrolysis of lignocellulose biomass will result in a breakthrough in the field of biofuels production. The net contribution of biofuels to the total energy consumption is $0.8 \%$, with a majority of the fraction being contributed by fossil fuels (79\%) with the rest being contributed by other renewables (17.2\%) and nuclear energy $(3 \%)$. In the next 30 years, it is expected that $27 \%$ of the transportation energy comes from biofuels. It is possible, if microwave based transesterification and biomass hydrolysis methods are scaled up for large scale production [3-5]. Use of solar energy for biofuels should be encouraged [6].

\section{Acknowledgements}

Grateful thanks are due to Professor Xinling Wang, Shanghai Jiao Tong University, for providing the employment to $\mathrm{Dr}$ Pulidindi in the time of need, the calm working environment and the needed resources for accessing scientific literature that has facilitated the compilation of the manuscript. Generous funding from the Israel Science Foundation (Grant number 598/12), Israel Ministry of Energy (Grant number 204512) and the Israel Ministry of National infrastructures, Energy and Water resources (Grant number 216-11-015) supporting the work is acknowledged with thankfulness.

\section{References}

1. Nomanbhay S, Ong MY (2017) A review of microwave-assisted reactions for biodiesel production. Bioengineering 4: 57. Link: https://bit.ly/3rEl4xb

2. Liu J, Jia G (2017) Non-thermal effects of microwave in sodium chloride aqueous solution: Insights from molecular dynamics simulations. Journal of Molecular Liquids 227: 31-36. Link: https://bit.ly/36ZQFBy

3. Pulidindi PI, Kimchi BB, Gedanken A (2014) Can Cellulose be a sustainable feedstock for Bioethanol production? Renewable Energy 71: 77-80. Link: https://bit.ly/3p6rsfc

4. Pulidindi PI, Gedanken A (2020) The catalytic production of biofuels (Biodiese and Bioethanol) using sonochemical, microwave and mechanical methods. In B. Torok and C. Schaefer (Eds), Non-traditional Activation methods in green and sustainable applications: Microwaves, ultrasound, photo, electro and mechanochemistry and high hydrostatic pressure (1st Ed, chapter 6). Elsevier.

5. Pulidindi PI, Gedanken A (2019) Can Biofuels Alleviate the Energy and Environmental Crisis? Nova Science Publishers, Inc., New York. Link: https://bit.ly/3cXxpbK

6. Pulidindi PI, Gedanken A (2021) Solar intervention in bioenergy. In Sanjay Sahay (Ed) Hand book of Biofuels (1st Ed., Chapter 36). Elsevier.

\footnotetext{
Discover a bigger Impact and Visibility of your article publication with

Peertechz Publications

Highlights

* Signatory publisher of ORCID

* Signatory Publisher of DORA (San Francisco Declaration on Research Assessment)

* Articles archived in worlds' renowned service providers such as Portico, CNKI, AGRIS, TDNet, Base (Bielefeld University Library), CrossRef, Scilit, J-Gate etc.

* Journals indexed in ICMJE, SHERPA/ROMEO, Google Scholar etc.

* OAl-PMH (Open Archives Initiative Protocol for Metadata Harvesting)

* Dedicated Editorial Board for every journal

* Accurate and rapid peer-review process

- Increased citations of published articles through promotions

* Reduced timeline for article publication

Submit your articles and experience a new surge in publication services (https://www.peertechz.com/submission).
}

Copyright: (C) 2021 Pulidindi IN, et al. This is an open-access article distributed under the terms of the Creative Commons Attribution License, which permits unrestricted use, distribution, and reproduction in any medium, provided the original author and source are credited. 